\title{
Estimation and Analysis of Mefenamic Acid Suspension; A Proportional Investigation
}

\author{
Safila Naveed ${ }^{1 *}$, Fatima Qamar ${ }^{1}$, Syeda Sarah Abbas ${ }^{1,2}$, Sadia Safdar ${ }^{1}$, Sana Ameer ${ }^{1}$ and \\ Ummeshah Idrees $^{1}$ \\ ${ }^{1}$ Faculty of Pharmacy, Jinnah University for women, Karachi, Pakistan \\ ${ }^{2}$ Faculty of Pharmacy, University of Karachi, Karachi, Pakistan
}

Received: September 04, 2015; Accepted: October 09, 2015; Published: December 08, 2015

*Corresponding author: Safila Naveed, Faculty of Pharmacy, Jinnah University for women, Karachi, Pakistan, Email: safila117@yahoo.com; fatimamudassar2009@hotmail.com

\begin{abstract}
Suspensions form an important class of pharmaceutical dosage forms. Pharmaceutical suspension may be defined as a coarse dispersion containing finely divided insoluble material suspended in a liquid medium. Desirable properties of suspensions are that they should have good organoleptic properties, suspensions should possess good pourability leading to ease of removal of dose from container, the particle size distribution should be uniform, there should be ease of re dispersion of settled solid particles, they should be physically and chemically stable, and they should be resistant against microbial contamination. Mefenamic Acid is a member of the fenamate group of nonsteroidal anti-inflammatory drugs (NSAIDs). It is rapidly absorbed after oral administration; it binds the prostaglandin synthetase receptors COX-1 and COX-2, inhibiting the action of prostaglandin synthetase. There was certain tests performed on mefenamic acid suspension to assess its quality, the methods are used to compare the three brands of suspension. First pH of all three brands were determined, then viscosity was checked by Ostwald viscometer after that sedimentation rate was determined by using $100 \mathrm{ml}$ measuring cylinder and in the end spectrophotometric analysis were performed. By performing the different procedure on three different formulations of mefenamic acid that are ponstan, dolor and mefnac, we conclude that ponstan gives good results as compare to dolor and mefnac.
\end{abstract}

Keywords: Suspension; Mefenamic acid; Quality control test; Types; Mechanism; Structure activity relationship

\section{Introduction}

Suspensions form an important class of pharmaceutical dosage forms. These disperse systems present many formulations, stability, manufacturing, and packaging challenges [1]. A Pharmaceutical suspension may be defined as a coarse dispersion containing finely divided insoluble material suspended in a liquid medium. The physical chemist defines the word "suspension" as two-phase system consisting of an undissolved or immiscible material dispersed in a vehicle (solid, liquid, or gas).Generally pharmaceutical suspensions contain aqueous dispersion phase, however in some cases they may be an oily or organic phase. The suspensions have dispersed particles above the colloidal size i.e. mean particle diameter above $1 \mu \mathrm{m}$. Suspensions should have good organoleptic properties, they should possess good pourability that eases the removal of dose from container. The particle size distribution should be uniform. There settled solid particles should be easily redispersed on shaking. They should be physically and chemically stable. They should be resistant against microbial contamination [7]. Classification of suspension is as follows:

1. According to the route of administration there are oral suspensions, topical suspensions, parental suspensions, ophthalmic suspensions.

2. According to the electro kinetic nature of solid particles there are flocculating suspensions and non-flocculating suspensions.

3. According to the proportion of solid particle there are Dilute suspension (2 to $10 \% \mathrm{w} / \mathrm{v}$ solid) Concentrated suspension (50\%w/v solid) [1].

The physical stability of a pharmaceutical suspension requires that particles don't aggregate and they must be uniformly distributed throughout the dispersion medium. In order to achieve this ideal situation the additives are added to achieve ease in resuspension by a moderate amount of agitation [7]. The quality control tests of suspensions are:

1. Sedimentation volume: Redispersibility is the major consideration in assessing the acceptability of a suspension. The measurement of the sedimentation volume and its ease of redispersion form two of the most common basic evaluative procedures. The sedimentation volume is the simple ratio of the height of sediment to initial height of the initial suspension. The larger the value better is the suspendability.

2. Particle size and size distribution: The freeze-thaw cycling technique used to assess suspension for stress testing for stability testing result in increase of particle growth and may indicate future state after long storage. It is of importance to study the changes for absolute particle size and particle size 
distribution. It is performed by optical microscopy, sedimentation by using Andreasen apparatus and Coulter counter apparatus. None of these methods are direct methods. However microscopic method allows the observer to view the actual particles. These dimentation method yields a particle size relative to the rate at which particles settle through a suspending medium.

3. Rheological studies: Rheologic methods can help in determining the settling behaviour of the suspension. Brookefield viscometer with variable shear stress control can be used for evaluating viscosity of suspensions. It consist of T-bar spindle which is lowered into the suspension and the dial reading is noted which is a measure of resistance the spindle meets at various levels in the suspension. This technique also indicates in which level of the suspension the structure is greater due to particles aggregates. Data obtained on aged and stored suspension reveals whether changes have taken place.

4. Stability testing: It is not possible to conduct accelerated temperature studies as it can be done in solutions. The formulation exhibiting thixotropic properties a rise in temperature would change the properties. In this physical form, the preparation would exhibit parameters that could not be extrapolated to those that would exist in the normal system. The valid temperature data could be obtained that will be useful in the estimation of the physical stability of a product at normal storage conditions. The extended aging tests must be employed under various conditions to obtain the desired information [5].

Mefenamic Acid's purity was confirmed by testing its melting point and by examining it using the IR spectrum. All the solvents were of pure laboratory grade and were purchased from $\mathrm{CDH}$ (Mumbai, India) [4]

Mefenamic Acid is a member of the fenamate group of nonsteroidal anti-inflammatory drugs (NSAIDs). Mefenamic Acid is a white to greyish-white, odorless, microcrystalline powder with a melting point of $230^{\circ}$ to $231^{\circ} \mathrm{C}$ and water solubility of $0.004 \%$ at $\mathrm{pH} 7.1$. The chemical name is $\mathrm{N}-2,3$-xylylanthranilic acid. The molecular weight is 241.29 . Its molecular formula is C15H15N02 [2].

Its pharmacokinetics: Mefenamic Acid is rapidly absorbed after oral administration. Mefenamic Acid has been reported as being greater than $90 \%$ bound to albumin. Mefenamic acid undergoes metabolism by CYP2C9 to 3-hydroxymethyl mefenamic acid, and further oxidation to a 3-carboxymefenamic acid may occur [3].

The mechanism of action is mefenamic acid binds the prostaglandin synthetase receptors COX-1 and COX-2, inhibiting the action of prostaglandin synthetase. Mefenamic acid is available as suspension in strength $50 \mathrm{mg}, 100 \mathrm{mg}, 50 \mathrm{mg} / 5$ $\mathrm{ml}, 100 \mathrm{mg} / 5 \mathrm{ml}, 250 \mathrm{mg} / 5 \mathrm{ml}$ and tablets of $250 \mathrm{mg}$ and 500 mg [6].

The SAR of mefenamic acid can be described as if NH group is replaced the less active compound would be produced thus esters and ketones are inactive, Carboxylic group is required for biological activity if it is replaced with isosterictetrazole antiinflammatory activity would be lost [8].

\section{Methodology}

In this experiment we are comparing three brands of mefenamic acid suspension; Ponstan (Formulation A), Mefnac (Formulation B) and Dolor (Formulation C). We performed the following tests to compare these suspensions: $\mathrm{pH}$ determination: We took the formulation A, B and C in three separate beakers and then one by one observed the $\mathrm{pH}$ of these marketed suspensions with the help of $\mathrm{pH}$ meter. Viscosity: We used Ostwald viscometer for determination of the viscosity. We filled viscometer with the suspension and bring it up till the upper desired mark then we start the stop watch and note down the time till the suspension reaches the lower mark.

Sedimentation: We filled three $100 \mathrm{ml}$ measuring cylinder with formulation $\mathrm{A}$, formulation $\mathrm{B}$ and formulation $\mathrm{C}$ and marked them respectively and noted the readings after $48 \mathrm{hrs}$.

Spectrophotometer Analysis: We took one ml of suspension in $100 \mathrm{ml}$ volumetric flask and dissolved it in small amount of methanol and then make up the volume with distill water. By doing this we made a stock solution of $10 \mathrm{ppm}$. From this stock solution $1 \mathrm{ml}$ was taken and made another $100 \mathrm{ml}$ dilution, this is 1st dilution. The concentration of this dilution is 0.1. After that we took $1 \mathrm{ml}$ solution from this 1 st dilution and made 2 nd dilution, of concentration 0.01 .

\section{Result}

We observed the $\mathrm{pH}$ of formulation $\mathrm{A}, \mathrm{B}$ and $\mathrm{C}$. The $\mathrm{pH}$ of formulation $\mathrm{A}$, formulation $\mathrm{B}$ and formulation $\mathrm{C}$ were determined as: [table, 1].

After that we determined the viscosity of the three suspensions. The viscosity can be found by formula:

\section{$n=$ (density of suspension $\times$ time taken by suspension)/ (density of waterxtime taken by water)}

This was performed by Ostwald viscometer, the time taken by formulation A, formulation B and formulation C were: [table, 2]

Then the sedimentation rate was determined, and the results are: [table, 3] Then we performed the spectrophotometeric analysis of the formulations. [table, 4]

\section{Discussion}

We performed different tests on three brands of mefenamic acid suspension. Firstly we performed $\mathrm{pH}$ testing on these suspensions which shows that formulation $\mathrm{A}$ is less acidic as compare to formulation $\mathrm{B}$ and $\mathrm{C}$. Then we performed the viscosity testing on these suspensions and only formulation $\mathrm{A}$

\begin{tabular}{|c|c|}
\hline Table 1: $\mathrm{pH}$ of different suspension of Mefenamic acid. \\
\hline Formulation & $\mathbf{p H}$ \\
\hline Formulation A & 5.81 \\
\hline Formulation B & 4.61 \\
\hline Formulation C & 4.56 \\
\hline
\end{tabular}


showed results, it moved from one mark to other in $30 \mathrm{~min}$ and $25 \mathrm{sec}$. the other two formulation did not show the results. This can be due to two reasons i) the particle size distribution was not uniform in formulation $\mathrm{B}$ and $\mathrm{C}$ or ii) the suspending agent used in both formulation was too viscous. The sedimentation rate testing showed that the particles in formulations are well suspended and there are a very less chances of cake formation. With the spectrophotometeric analysis we found that ponstan has maximum absorbance than other two formulations. (A > C $>$ B). The spectrophotometer analysis can be explained as Fig: 1 .

\section{Conclusion}

By performing the different procedure on three different formulations of mefenamic acid that are ponstan, dolor and mefnac, we conclude that ponstan gives good results as compare to dolor and mefnac.

Table 2: Time taken of different suspension of Mefenamic acid.

\begin{tabular}{|l|c|}
\hline Formulation & Time taken by suspension \\
\hline Formulation A & $30 \mathrm{~min} 25 \mathrm{sec}$ \\
\hline Formulation B & Not determined \\
\hline Formulation C & Not determined \\
\hline
\end{tabular}

Table 3: Sedimentation volume of different suspension of Mefenamic acid.

\begin{tabular}{|c|c|}
\hline Formulation & Sedimentation volume \\
\hline A & $92 \mathrm{ml}$ \\
\hline B & $91 \mathrm{ml}$ \\
\hline C & $97 \mathrm{ml}$ \\
\hline
\end{tabular}

Table 4: Absorbance of different dilution of different suspension of Mefenamic acid.

\begin{tabular}{|c|c|c|c|}
\hline Concentration: & $\begin{array}{c}\text { Formulation A } \\
\text { Absorbance: }\end{array}$ & $\begin{array}{c}\text { Formulation B } \\
\text { Absorbance: }\end{array}$ & $\begin{array}{c}\text { Formulation C } \\
\text { Absorbance }\end{array}$ \\
\hline Stock solution & 3.208 & 2.246 & 2.469 \\
\hline $1^{\text {st }}$ dilution & 0.088 & 0.054 & 0.070 \\
\hline $2^{\text {nd }}$ dilution & 0.033 & 0.034 & 0.010 \\
\hline
\end{tabular}<smiles>Cc1cccc(Nc2ccccc2C(=O)O)c1C</smiles>

Figure 1: Structure of Mefenamic acid.

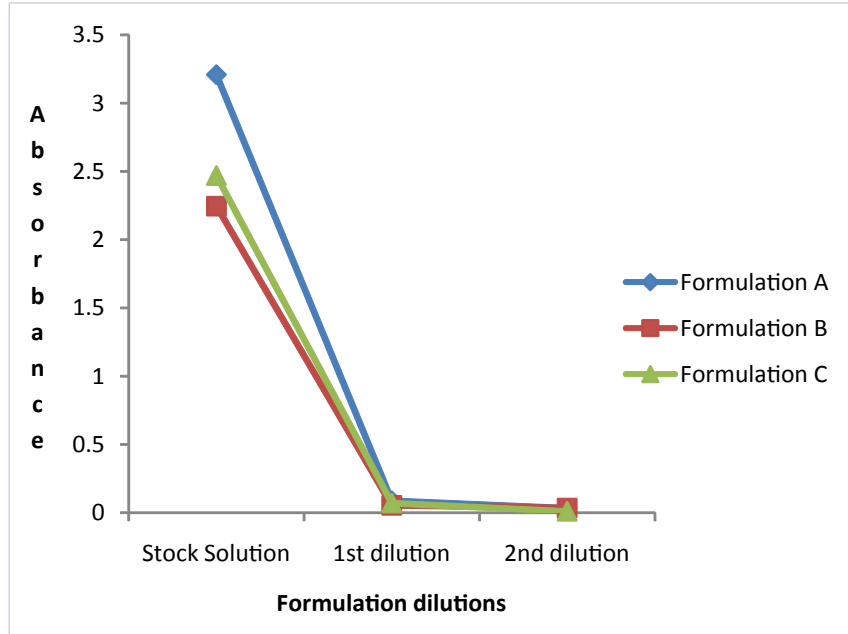

Figure 2: Absorbance of different dilution of different suspension of Mefenamic acid.

\section{References}

1. 0921py. A Report on Pharmaceutical Suspension. 2014

2. Glazko AJ. Experimental observations of flufenamic, mefenamic, and meclofenamic acids. Part III. Metabolic disposition, in Fenamates in Medicine. Annals of Physical Medicine. 1966; Suppl:23-36.

3. Joo Y, Kim HS, Woo RS, Park CH, Shin KY, Lee JP, Chang KA, et al. Mefenamic acid shows neuroprotective effects and improves cognitive impairment in in vitro and in vivo Alzheimer's disease models. Mol Pharmacol. 2006;69(1):76-84.

4. KC George. Preparation and stability of suspensions of small particles. 2010.p.13-25

5. Anand Patel. Quality control tests for suspensions. Published on 2011 Feb 07

6. Sinniah R, Lye WC. Acute renal failure from hemoglobinuric and interstitial nephritis secondary to iodine and mefenamic acid. ClinNephrol. 2001;55(3):254-258.

7. Suspension, Published by: neil vidhya on Oct 13,2010

8. V. Alagarsamy. Textbook of Medicinal Chemistry. Vol II. Elsevier. 2010. P-71. 